\title{
A Case Study about Accuracy and Fluency in Teaching Chinese as a Second Language
}

\author{
LI Mengke
}

The University of Hong Kong

\begin{abstract}
This case study aims to address how to promote accuracy in the main stream of focusing on fluency. During the period of data collecting, face to face interviewing is used to get some ideas about the relationship between accuracy and fluency when students learning Chinese from Chinese teachers in one Hong Kong International School. Observing in the real classes is also used to collect the teaching strategies when they put their ideas into practice. After sorting the relative data, the average result is that around half of the teaching activities are about accuracy, while there are more fluency-oriented activities in the higher level classes. As for the teaching methods, focusing on form is the most popular, but focusing on forms is also not ignored. When correcting the errors, correcting directly, indirectly correcting such as repeat the error and interaction modification are utilized a lot in the classes.
\end{abstract}

Key words: accuracy, fluency, speaking, TCSL

\section{Introduction}

In the area of second language acquisition, it is a time of focus on meaning (fluency) instruction. Many scholars believe that the obtainment of accuracy can naturally get during the period of comprehensible input just like the first language acquisition (Krashen, 1985). But many scholars argue that accuracy should not be abandoned in this main trend. Because through a large number of data, it is obviously that there are still many grammar errors even though the students get the high level of fluency (Lzumi, 1999). So Doughty and Williams (1998) consider that changing the attitude toward forms when doing communicative activities is of necessity.

This case study aims to discover and summarize some effective teaching strategies about how to pay more attention to accuracy when making the fluency training in the teaching Chinese as a second language class. As for collecting the data, face to face interviewing and observing in the real classes will be used to analyze the ideas about the conception of accuracy and fluency of some Chinese teachers in one Hong Kong International School and the ways they put their ideas into practice to develop the students.

\section{Literature Review}

\section{Definition of the Key Terms}

Accuracy: Vocabulary, grammar and pronunciation are regarded as the three important elements of accuracy ( Gower, Phillips \& Walter, 2005). If the way a speaker to use one language is not the same as that of a native speaker, including all of the three elements, he will be treated as lacking of accuracy. In another word, that is error. (Ellis, 2008).

Fluency: Fluency is a concept, which is related to a learner's general language proficiency (Chambers, 1997). And there are three key ways to judge a speaker's fluency, which are the speed, the breakdown and the repair (Tavakoli \& Skehan, 2005). If a person can transfer the information smoothly and the listeners can get the point, regardless of the grammar rules he uses is right or not, he will be regarded as a fluent speaker (Hunter, 2011).

Relationship

In the history of second language acquisition, the relationship between accuracy and fluency has changed several times. About 100 years ago, learning a foreign language almost meant 
learning grammar and structures, which was about accuracy. To some degree, learning grammar perfectly was regarded as the end of learning a foreign language. (Alexander, 2006)

As the development of educational researches, communicative approach begins to paly a main role in sound language acquisition. Some scholars, Corder (1967) and Krashen (1985) for example, through comparing the way first language acquisition by young children, point that comprehensible input is also sufficient enough for the second language or foreign language learners. The immersion program in Canada is a good example of this hypothesis. Students get a variety of comprehensible input. And the result of this kind of education is obvious, which is that the students can speak the target language very fluently at the end of the program. Whereas, with the procession of the studies, much evidence is found that it is not sufficient enough for a second language learner, because most of the students in the immersion class show the different level of weakness in the accuracy of grammar and the using of vocabulary (Harley, 1993).

At this period, a debate about the relationship between accuracy and fluency become lively again. Long and Robinson (1998) consider that it is not enough for learners to learn the target language only focus on meaning, because the lack of accuracy will result in fossilization, which the errors of grammar will be revised difficultly (Brown, 2000). So more and more researchers call on paying more attention to accuracy. Nowadays, the most acceptable concept is putting some special activities to let the second language learners transfer the attention to accuracy when doing the communicative practice (Doughty and Williams, 1998). In other words, trying to find a way to make the two dimensions balance (LIU Songhao, 2005).

Hypothesis

Focus on form is a kind of learner-centered instruction (Ellis, 2008), which is based on the Interaction Hypothesis (Long, 1983). This form is a kind of instruction that teaching grammar, rules and functions in a communicative background. This instruction has been evidenced to be helpful for the improving of the accuracy of the second language grammar (Doughty \& Williams, 1998). Ellis (2003) argues that there three different ways to design a focused task. They are Structured based task, Comprehension task and Consciousness-raising task.

Smith (1981) points that consciousness raising is a way that lecturers let learners raise consciousness to the forms of the target language by changing the way to input to promote the accuracy of the second language. According to the researches, generally there exists two ways to make the learners' consciousness rise. One is deductive approach, where learners are taught the rules and regularities by the lecture directly (Sheen, 1992). The other one is inductive approach, where learners are told to find the accurate forms by themselves (Bourke, 1996). However, there is no significant evidence to judge which kind of approach that learners show more preference (Mohamed, 2004). JIN Honggang (2005)points that typographic enhancement, intonation enhancement and the choice of emphasis enhancement are the three ways to enhance input.

Swain (1985) proposed the Output Hypothesis (1985) and argues that not only the comprehensible input is needed in the process of second language acquisition, but also the comprehensible output. Then she has extended her hypothesis to three main functions of the output (1993, 1995). They are testing, metalinguistics and noticing/ triggering or consciousness-raising. During the procession of making production of the target language, learners can discover the divide between the sentences that they desire to say and the sentences that they finally say, which can spark them to notice where they are weak in, which part they need to improve. 
In conclusion, there are many theories, hypothesizes and discussions about accuracy and fluency. Actually, there are not many theses about the relationship between accuracy and fluency or how to balance the two dimensions in teaching spoken Chinese as a second language. So this case study is aiming for testing if Chinese as a second language teacher agree the current theories or not, and what their specific teaching strategies when learners meet some trouble about accuracy, and trying to find some more valuable experience typically for teaching Chinese as a second language.

\section{Method}

\section{Participants}

Participants are 4 Chinese Mandarin teachers from one International School in Hong Kong and all of them have more than 10-year teaching experience. Moreover, the students in this international school are vary ages from 12 to 18 years old and in quite different levels, so it will be not that difficult to find teachers' different and common aspects about the views and teaching strategies for the different ages and levels about the two dimensions of accuracy and fluency.

\section{Research instruments}

Two data sources will be adopted. They are face-to-face interview and classroom observations.

\section{Interview.}

The purpose of the interview is to explore teachers' understanding, notions, attitudes towards accuracy and fluency in spoken Chinese teaching. Each teacher will be interviewed individually in Chinese Mandarin for at least 20 minutes.

\section{Class observations.}

The class observations were processed after the interview. There are two main purposes of the class observations. First, test if the teachers put their ideas which were pointed in the interview into the real teaching condition. Second, find the effective teaching methods for improving the accuracy of spoken Chinese.

In this case study, a chart was used in class observations, and the actual teaching activities were recorded accurately. The whole class observations were lasted about 2 months and a half. Each teacher was observed at least 9 times, including different levels of students, and each time was last 40 minutes.

\section{Procedures}

The whole case study was last for four months. Four Chinese teachers were invited in this pilot test process. It began with the pilot test of the interview. Based on the interviews, class observations were hold to discover how the teachers put their ideas into teaching practice. The interview questions will be pilot tested for the validity and appropriateness, and the class observation chart will be pilot tested for its validity and applicability.

\section{Data analysis.}

The Interview data is collected as following. All of the four teachers prefer fluency to accuracy when make oral practice, and consider that developing the ability of communicating is the most important, but they still argue that accuracy cannot be ignored. Only teacher C holds the opinion that accuracy should only be taken into consideration when making input, while others agree that it should be paid attention to in both input and output practice. However, when they are interviewed about making writing practice, even though there are some different specific strategies, all of them transfer their attention form fluency to accuracy. Teacher A describes that being more strict in grammar when doing writing assignment is because writing down the right forms for students can raise their awareness of the errors more effective than just telling them. While Teacher B and Teacher D consider that doing like this because they want students get better grades in the exams. 
The class observations data is collected as following.

Chart 1 Introduction of the data background

\begin{tabular}{|l|c|c|c|c|c|c|c|c|c|c|c|c|c|}
\hline \multirow{2}{*}{} & \multicolumn{4}{|c|}{ Teacher A } & \multicolumn{3}{c|}{ Teacher B } & \multicolumn{2}{c|}{ Teacher C } & \multicolumn{4}{c|}{ Teacher D } \\
\cline { 2 - 14 } & Y7 & Y8 & Y10 & Y12 & Y8 & Y9 & Y12 & Y9 & Y12 & Y7 & Y8 & Y10 & Y11 \\
\hline \multicolumn{1}{|c|}{ Level } & E & A & E & I & E & E & A & A & A & E & E & I & I \\
\hline $\begin{array}{l}\text { The } \\
\text { knowledge } \\
\text { of Chinese } \\
\text { characters }\end{array}$ & 300 & 2500 & 700 & 1200 & 800 & 700 & 2600 & 2300 & 2700 & 700 & 800 & 1200 & 1300 \\
\hline $\begin{array}{l}\text { Observation } \\
\text { times }\end{array}$ & 3 & 2 & 2 & 2 & 2 & 4 & 3 & 3 & 6 & 2 & 2 & 2 & 3 \\
\hline
\end{tabular}

$E$ stands for Elementary; I stands for Intermediate; $A$ stands for Advanced The date of the class observations is present by two charts. One is about teaching strategies and the other one is about teachers' methods of correcting errors.

Chart 2 the statistical result of teaching strategies

\begin{tabular}{|c|c|c|c|c|c|c|c|c|c|c|c|c|c|c|}
\hline \multirow{3}{*}{\multicolumn{2}{|c|}{ Teaching strategies }} & \multicolumn{13}{|c|}{ Using times } \\
\hline & & \multicolumn{4}{|c|}{ Teacher A } & \multicolumn{3}{|c|}{ Teacher B } & \multicolumn{2}{|c|}{ Teacher C } & \multicolumn{4}{|c|}{ Teacher D } \\
\hline & & Y7 & Y8 & $\begin{array}{c}\mathrm{Y} \\
10\end{array}$ & $\begin{array}{l}\mathrm{Y} \\
12\end{array}$ & Y8 & Y9 & $\begin{array}{c}\mathrm{Y} \\
12 \\
\end{array}$ & Y9 & $\begin{array}{l}\mathrm{Y} \\
12 \\
\end{array}$ & Y7 & Y8 & $\begin{array}{c}\mathrm{Y} \\
10\end{array}$ & $\begin{array}{c}\mathrm{Y} \\
11\end{array}$ \\
\hline \multicolumn{2}{|c|}{$\begin{array}{l}\text { Directly grammar } \\
\text { teaching }\end{array}$} & 12 & 2 & 7 & 11 & 9 & 21 & 5 & 7 & 16 & 11 & 12 & 10 & 14 \\
\hline \multicolumn{2}{|c|}{\begin{tabular}{|l|} 
Conversation \\
making \\
(Fluency-oriented \\
activities) \\
\end{tabular}} & 26 & 27 & 19 & 29 & 18 & 33 & 32 & 30 & 61 & 25 & 23 & 28 & 35 \\
\hline \multirow{2}{*}{$\begin{array}{l}\text { Pushe } \\
\text { d } \\
\text { output }\end{array}$} & $\begin{array}{l}\text { Conversatio } \\
\text { n making } \\
\text { (Accuracy- } \\
\text { oriented } \\
\text { activities) }\end{array}$ & 2 & 5 & 3 & 7 & 5 & 12 & 13 & 7 & 4 & 7 & 6 & 9 & 10 \\
\hline & $\begin{array}{l}\text { Sentences } \\
\text { making } \\
\text { (Accuracy- } \\
\text { oriented } \\
\text { activities) }\end{array}$ & 9 & 4 & 7 & 5 & 6 & 9 & 2 & 8 & 19 & 9 & 8 & 8 & 15 \\
\hline \multicolumn{2}{|c|}{$\begin{array}{l}\text { The percentage of } \\
\text { accuracy-oriented } \\
\text { activities }\end{array}$} & $\begin{array}{l}47 \\
\%\end{array}$ & $\begin{array}{l}29 \\
\%\end{array}$ & $\begin{array}{l}47 \\
\%\end{array}$ & $\begin{array}{l}44 \\
\%\end{array}$ & $\begin{array}{l}53 \\
\%\end{array}$ & $\begin{array}{l}56 \\
\%\end{array}$ & $\begin{array}{l}38 \\
\%\end{array}$ & $\begin{array}{l}42 \\
\%\end{array}$ & $\begin{array}{l}39 \\
\%\end{array}$ & $\begin{array}{l}52 \\
\%\end{array}$ & $\begin{array}{l}53 \\
\%\end{array}$ & $\begin{array}{l}49 \\
\%\end{array}$ & $\begin{array}{l}53 \\
\%\end{array}$ \\
\hline
\end{tabular}


Chart 3 the statistical result of feedback when correcting the errors

\begin{tabular}{|c|c|c|c|c|c|c|c|c|c|c|c|c|c|c|}
\hline \multirow{3}{*}{$\begin{array}{l}\text { Method of } \\
\text { correcting }\end{array}$} & \multicolumn{14}{|c|}{ Using times } \\
\hline & \multicolumn{4}{|c|}{ Teacher A } & \multicolumn{3}{|c|}{ Teacher B } & \multicolumn{2}{|c|}{ Teacher C } & \multicolumn{4}{|c|}{ Teacher D } & \multirow[t]{2}{*}{ Tota } \\
\hline & Y7 & Y8 & Y10 & Y12 & Y8 & Y9 & Y12 & Y9 & $\mathrm{Y} 12$ & Y7 & Y8 & Y10 & Y11 & \\
\hline Directly correct & 15 & 3 & 11 & 10 & 9 & 21 & 8 & 12 & 20 & 10 & 9 & 11 & 16 & 165 \\
\hline Repeat the error & 7 & 4 & 7 & 5 & 3 & 9 & 10 & 8 & 19 & 5 & 4 & 5 & 6 & 92 \\
\hline $\begin{array}{l}\text { Interaction } \\
\text { modification }\end{array}$ & 6 & 7 & 6 & 8 & 6 & 15 & 8 & 9 & 15 & 7 & 6 & 8 & 11 & 112 \\
\hline Peer helper & 9 & 5 & 6 & 6 & 3 & 11 & 9 & 4 & 13 & 5 & 4 & 7 & 9 & 91 \\
\hline
\end{tabular}

From the chart 1, it can be seen that there are six elementary classes, three intermediate classes and four advanced classes being observed. Form the chart 2, Teacher $\mathrm{A}$ and Teacher $\mathrm{C}$ focused on fluency a little bit more than the other two teachers, while Teacher $\mathrm{B}$ and Teacher $\mathrm{D}$ preferred developing accuracy more. Generally, combining with what the teacher said in the interviews, it can be discovered that even through all of the teachers said that fluency plays a more important role in teaching Chinese as a second language, they still paid much attention to accuracy when teaching. The accuracy-oriented activities, including directly grammar teaching, took a percentage of approximately $46 \%$ in all the teaching activities, which nearly occupied half. Moreover, almost the advanced classes got more fluency-oriented activities than elementary and intermediate ones, whose percentages were clearly under the average number.

In the chart 3 , according to the total times, it was obvious that all the teachers' favorite way to correct students' errors was directly correcting, which took a percentage of $36 \%$, and the next was Interaction modification (24\%). Repeat the error and peer helper occupied around $20 \%$ respectively. The details were described in the bar chart.

Chart 4 the total numbers of the correcting methods

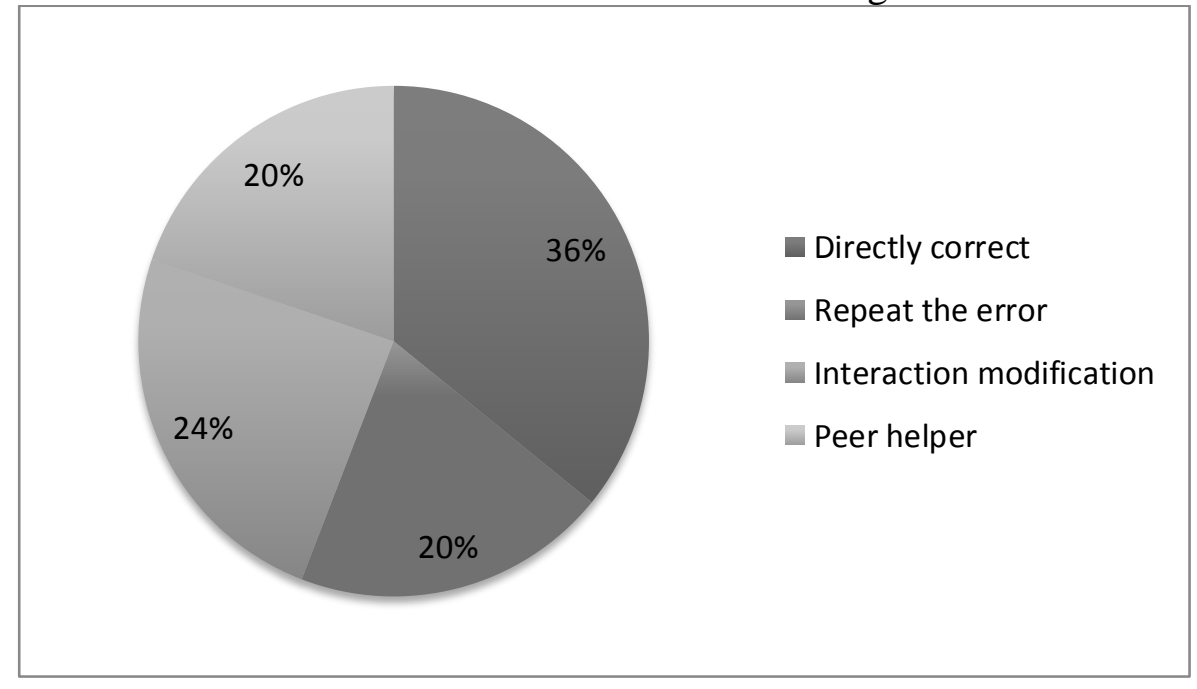




\section{Results}

According to all of the data, what Teacher A and Teacher B said and what they did in the real classes generally matched. But as for Teacher $\mathrm{C}$, even though she argues that developing the ability of communicating is the most important and some errors should be ignored, she still pays much attention to correct students' grammar errors. And teacher D, who advocates that just understanding by listeners is enough, even corrects students' errors more frequently than other teachers. That is to say, according to the behaviors of the four teachers, when the teachers face that students make errors, it is unavoidable to correct them sometimes. What is more, most of the four teachers prefer directly grammar teaching to teach students using the target language correctly. And following the distribution of teaching strategies, the teaching structure consisting of around half accuracy training and half fluency training is always for the elementary and intermediate students. Then the higher level of Chinese the students have, the more fluency training they will get.

There are many methods for teachers to correct students' language errors. But directly correcting is still very popular. Moreover, it can be seen that directly correcting is utilized more in the lower level classes more than the higher level classes, while indirectly correcting is more used in the higher level classes.

\section{Discussion}

This case study investigated two main questions. One was testing if what the participant said matched with what they really did in the real class. The other one was discussing some effective methods for teaching Chinese as a second language.

It is surprised that only half of the participants generally put their teaching ideas into practice. This result indicated that accuracy is still very significant in many teachers mind, even though they know they should pay more attention to fluency training. This phenomenon maybe depends on the teaching environment. Because almost teachers hope their students get good grades in the exams, so they must pay more attention to accuracy. Although there are some conflicts between what they said and what they did, it is not wrong to point out the errors for the students. However, the literature also statements that grammar is just a system to support people communicating (Alexander, 2006). So are all these teaching strategies and error-corrections effective for improving the ability of communicating?

Focus on forms, Focus on Form, Focus on meaning

According to the results of the class observations, directly grammar teaching, which can be regarded as both input and focusing on forms instruction, is still very popular. Thus, students can learn the language rules and forms directly and improve the accuracy of Chinese speaking. However, because focusing on forms instruction is a teacher-centered activity, so students may feel tired and bored in the class.

Besides focusing on forms, there are many teaching strategies being related to focusing on form according to the results, such as conversation making and sentences making. In these ways, leaners can pay attention to accuracy in the communicative condition, so learners can improve the ability of accuracy and communicating at the same time. Meanwhile, this is not only a good way to teach grammar, but also teach vocabulary (Doughty \& Williams, 1998). While, nearly half of the teaching activities are focusing on meaning, which means training learners' language ability by communicating and ignoring the unsuitable forms they use (Long \& Robinson, 1998). To some degree, focusing on forms and focusing on form can be regarded as accuracy-oriented and focusing on meaning can be regarded as fluency-oriented. Combining with both of the two kinds of activities in teaching is a good way to improve both accuracy and fluency.

Distribution

What is the best percentage to distribute the different teaching activities? From the results 
we can see that accuracy-oriented activities and fluency-oriented activities occupy approximately half respectively in the elementary and intermediate classes, while students in the advanced classes get more fluency training. Generally speaking, if it is the first time for a learner to touch a foreign language, focusing on accuracy first is better, because the learner even does not have the idea of fluency (Brumfit, 1984). That is to say, it is reasonable to pay more fluency as the level increasing. And if the percentage of accuracy training is the best to occupy half or not, there will be more tests being put in the future.

\section{Correction}

According to many researches, corrective feedback is benefit to the development of accuracy and fluency (Sato \& Lyster, 2012). From the results, all the teachers give students correction feedback, while directly correcting is the most popular one in the four main ways, which is a deductive approach to raise learners' consciousness. And different ways of correcting are used in different levels. Direct correction can let learners know where the errors are very clearly, so it is more suitable for the beginners. Repeating the error and interaction modification are the two ways to raise learners' consciousness of the errors. It needs more skills for the lecturer to handle these ways of correcting than correcting directly, but should be get more recommendation, because learners can not only correct the errors, but also make the comparison between the regulations (Doughty \& Varela, 1998).

\section{Conclusions}

Overall, there is much information found in this case study. Firstly, in the main stream of paying attention to fluency, accuracy is still lively in the real classes. In the interviewed teachers' perspectives, most of them believe accuracy should be paid attention to when teaching Chinese. Even though there some conflicts between what they thought and what then really did, it is not obstructive to show that nearly half of the teaching activities are accuracy-oriented, and fluency is relatively paid more attention in higher level classes. By this kind of distribution, leaners can get enough fluency training, and get proper opportunities to improve the accuracy of the target language as well. But in terms of what the most ideal distribution is, the data is insufficient in this case study. Secondly, after comparing and discussing, focusing on form is a very reasonable way to combine accuracy training and fluency training. Because developing accuracy in a communicative way is more interested and meaningful. While even though focusing on forms is not recommended, it still should not be abandoned. The reason is that learners can gain the accuracy of target language directly. Focusing on meaning is apart form the above two and plays an important role to promote the ability of fluency, which is to achieve the main aim to learn a language. Thirdly, although correcting directly takes the highest percentage in the main four correcting methods, while the rest of the three almost belong to indirectly correcting. In other words, indirectly correcting is more popular. Moreover, according to the previous literatures, indirectly correcting has more advantages than directly correcting. Because learners could not only correct the errors, but also raise more consciousness by indirectly correcting. But using what kinds of ways to correct should take students' level into consideration. For beginners, directly correcting is better, but for the higher level students, using indirectly correcting to raise their consciousness should get more recommendation. In other words, if the lecture wants to get the best results of correcting, he should know the level of his students very well. However, this case study is too simple. Interviewing, observing in the classes and combine the results with the previous theories is not convictive enough, and if the teaching strategies and correcting ways are ideal or not quite lacks of data. So I plan to do an experimental research to test the results in this case study and find some more valuable information. 


\section{References}

[1] Alexander, L. (2006). Did you know that your command of English is a delicate balance between accuracy and fluency. Retrieved October 23, 2010, from http://www.

linguaphonegroup.com/learningad vice/accu racyfluency.cfm

[2] Bourke, J. (1996). In praise of linguistic problem solving. RELC Journal, 26(2), 1229.

[3] Brown, H. D. (2000). Principles of language learning and teaching ( $4^{\text {th }} \mathrm{ed}$.). New York: A Pearson Education Company.

[4] Brumfit, C. (1984). Communicative Methodology in Language Teaching. Cambridge: Cambridge University Press.

[5] Chambers, F. (1997). What do we mean by oral fluency? System, 25(4), 535-544.

[6] Corder, S. P. (1967). The significance of learner's errors. IRAL, 5, 161-170.

[7] Doughty, C., \& Varela, E. (1998). Communicative focus on form. In C. Doughty \& J. Williams (Eds.), Focus on form in classroom second language acquisition (pp. 114-138). Cambridge: Cambridge University Press.

[8] Ellis, R. (2003). Task-based language learning and teaching. Oxford: Oxford University Press.

[9] Gower, R., Phillips, D., \& Walters, S. (2005). Teaching practice handbook. Oxford: Macmillan Education.

[10]Harley, B. (1993). Instructional strategies and SLA in early French immersion. Studies in second language acquisition, 15, 245-260.
[11] Izumi, S., Bigelow, M., Fujiwara, M., \& Fearnow, S. (1999). Testing the output hypothesis: Effects of output on noticing and second language acquisition. Studies in second language acquisition, 21, 421-452.

[12]Jin, H. (2005). Form-focused instruction and second language learning: Some pedagogical considerations and teaching techniques. Journal of the Chinese language teachers association.40(2), 43-66.

[13] Krashen, S. (1985). The input hypothesis. Oxford: Pergamon Press.

[14]Long, M. H. (1983). Does second language instruction make a difference? A review of research. TESOL Quarterly, 17, 359-382.

[15] Mohamed, N. (2001) Teaching grammar through consciousness-raising tasks. Unpublished MA Dissertation. Auckland: University of Auckland.

[16]Saeidi, M., Zaferanieh, E., \& Shatery, H. (2012). On the effects of focus on form, focus on meaning, and focus on forms on learners' vocabulary learning in ESP context. English language teaching, 10, 7279.

[17]Sato, M., \& Lyster, R. (2012). Peer interaction and corrective feedback for accuracy and fluency development. Studies in second language acquisition, 34, 591626.

[18] Sharwood Smith, M. (1981). Consciousness-raising and the second language learner. Applied linguistics, 2, 159-168.

[19] Sheen, R. (1992). Problem solving brought to task. RELC Journal, 23 (3), 44-59.

[20]Swain, M. (1985). Communicative competence: Some roles of comprehensible input and comprehen- sible output in its 
development. In S. Gass \& C. Madden (Eds.), Input in second language acquisition (pp. 235-253). Rowley: Newbury House.

[21] Swain, M. (1993). The output hypothesis: Just speaking and writing are not enough. The Canadian modern language review, 50, 158-164.
[22] Tavakoli, P., \& Skehan, P. (2005) Strategic planning, task structure, and performance testing. InR. Ellis(Ed.), Planning and task performance in a second language (pp. 239-276). Amsterdam: John Benjamins. 